\title{
Memory Performance in Patient with Systemic Lupus Erythematosus Using MoCA-Ina in Hasan Sadikin Genneral Hospital Bandung
}

\author{
Safira Anjalia, ${ }^{1}$ Paulus Anam Ong, ${ }^{2}$ Nur Atik, ${ }^{3}$ Laniyati Hamijoyo ${ }^{4}$
}

\section{Faculty Medicine of Padjadjaran University, \\ ${ }^{2}$ Neurology Department; \\ ${ }^{3}$ Anatomy, Physiology, and Cell Biology Department: \\ ${ }^{4}$ Internal Medicine Departement, Faculty Medicine of Padjadjaran University / Dr. Hasan Sadikin General Hospital}

Correspondence: Safira Anjalia Jalan Raya BandungSumedang Km.21, Jatinangor, Sumedang Email:safiranjalia@ gmail.com
ABSTRACT

Background: The involvement of neuropsychiatry is reported in 6\% to $91 \%$ of Systemic Lupus Erythematosus (SLE) patients. It can cause fatal morbidity and mortality. Memory impairment is one of the most common symptoms of neuropsychiatry involvement. This study aims to find out the performance of memory test in SLE patients using Indonesian version of Montreal Cognitive Assessment (MoCA-Ina).

Method: This cross sectional study recruited 30 SLE patients. Cognitive abilities and patient's memory were examined using Indonesian version of Montreal Cognitive Assessment (MoCA-Ina). Cognitive impairment was determined when total MoCA-Ina score was below 26. For memory evaluation, immediate recall or delayed recall impairment was determined when the patient failed in each memory subtests.

Results: The mean of total MoCA-Ina score was 24.97 (SD \pm 3.14 ). Fifty percent of the SLE patients had cognitive impairment, with the domain involved being delayed recall (86.67\%), attention (60\%), language (56.67\%), abstraction (53.33\%), and visuo-spatial/ executive function (36.67\%). Most patients (86.67\%) could completely repeat immediate recall. While only 4 (13.33\%) subjects could repeat delayed recall completely without any clue. Of the 26 SLE patients who failed to recall completely, $24(92.3 \%)$ of them succeeded to recall completely after getting clue(s). Conclusion: Memory impairment is the most frequent cognitive impairment in SLE patients, especially in delayed recall. By using the memory subtests of MoCAIna, more than four fifth of patients with SLE was detected having delayed recall memory impairment and almost all of them could recalled completely after getting clue(s). This findings indicated that the final step of memory process retrieval in SLE was interrupted while being encoded, but retention pathway were still intact.

Keywords: Systemic Lupus Erythematous, Memory, MoCA-Ina

\section{Introduction}

The involvement of neuropsychiatry in Systemic Lupus Erythematous (SLE) patient was reported in $6 \%$ to $91 \%$ cases. It is known to cause fatal morbidity and mortality ${ }^{1,2}$ American College of Rheumatology (ACR) described 19 manifestation of neuropsychiaty SLE which classified into 2 main group, central nervous sytem manifestation and peripheral nervous system manifestation. ${ }^{1}$ One of the neuropsychiatry manifestation implied by ACR was cognitive impairment, which occured in $80 \%$ of neuropsychiatry lupus patient. ${ }^{2}$

According to previous study, SLE patients have lower cognitive ability than non-SLE. It is manifestated as impaired attention, visuospatial ability, working memory, and simple reaction time. ${ }^{1}$ Memory impairment is the most common manifestation. It is suggested that circulating antibody may inhibit neurotransmitter transmission and generate vasculopathy. ${ }^{1-3}$ As known, SLE mostly attacks females in their productive age. It would be very unfortunate if patients have memory impairment during their productive age, which would disturb their daily activities, impair their communication skills, and also reduce their quality of life.

MoCA and MMSE is the most common tools to assess memory and cognitive function in adult. MoCA has higher sensitivy in memory assessment than MMSE because it contained more words to be remembered, lesser opportunity for subjects to repeat, and longer time between immediate recall and delayed recall ${ }^{4,5}$

Theory about memory impairment in SLE patient had been mentioned in many journals. However,specific study about memory performance in SLE patient had not been studied yet, especially in Indoesia. The aim of this study is describing memory performance in SLE patient using MoCAIna in Hasan Sadikin General Hospital Bandung (RSHS).

\section{Method}

This quantitative-descriptive study with crosssectional method was conducted from September to November 2016. Subjects were obtained from Rheumatology Outpatient Clinic, Hasan Sadikin General Hospital, Bandung. Inclusion criteria of this study were age $\geq 18$ years old, fullfilled at least 4 of 11 American College of Rheumatology criteria for SLE which were stated in medical record, came for control with no or mild symptoms (low disease activity). Patient would be excluded if they had been diagnosed with central nervous 
system disorder before diagnosed as SLE patient. Sample was collected by consecutive sampling method.

Subject fullfilled inclusion and exclusion criteria will be assesed for their basic demographic and history of ilness, included age, gender, marital status, working status, level of education, disease duration, and whether patient had flare during the examination. Cognitive ability and memory was assesed using Montreal Cognitive Assesment Indonesian version (MoCA-Ina) in RSHS Memory clinic (Klinik Memori RSHS). Variable used in this study was demographic characteristic and the result of MoCA-Ina test in SLE patient.

MoCA test assesses visuo-spatial/executive ability, naming, attention, language, abstraction, memory, and orientation. MoCA subtests assess memory aspect, included immediate recall and delayed recall. In immediate recall, the examiner will spelled out 5 words, subjects will be requested to repeat the words two times. In delayed recall, subjects will be requested to repeat the same words at the end of MoCA test. If subjects are able to repeat all words directly without any clue, they will be scored 5. If necessary, categorical or multiple choice clues could be given. Cut off point for cognitive impairment is $26.4,6$

Data were analyzed using Microsoft Excel programs for calculating the mean, standard deviation, median, range for nummerical variable, and frequency (percentage) for categorical variable.

This study have been approved by Ethical Committee of Faculty Medicine of Padjadjaran University No.89/UN6. C1.3.2/KEPK/PN/2016 and Ethical Committe of Hasan Sadikin General Hospital No.LB.02.01/C02/8951/VII/2016.

\section{Result}

We involved 30 subjects. Most subjects are female (90\%) with mean age 35.3 years old, $70 \%$ were married and $56.7 \%$ subjects are not working or work as housewife. Most of SLE Patients $(60 \%)$ are high school graduate or equals. No subjects had high disease activity or in flare condition. Most of them came without any complaint or in the remission phase. Disease duration range from 1 month to 16 years, with median duration range of 4.21 years. Some subjects included in our study was reported having neuropsychiatric manifestation during the illness, such as headcache, vertigo, stroke, and seizure. Characteritic of study subjects are described in Table 1.

Table 1. Characteristic of SLE Patient at RSUP Dr. Hasan Sadikin

\begin{tabular}{lc}
\hline $\begin{array}{l}\text { Characteristic } \\
\mathrm{N}=30\end{array}$ & Results \\
\hline $\begin{array}{l}\text { Age (years) } \\
\text { Gender, freq }(\%) \\
\quad \text { Male }\end{array}$ & $35.3 \pm 10.47^{*}$ \\
$\quad$ Female & $3(10 \%)$ \\
Marital status, freq(\%) & $27(90 \%)$ \\
$\quad$ Married & \\
$\quad$ Not yet married & $21(70 \%)$ \\
Working, freq(\%) & $9(30 \%)$ \\
Working & \\
Not yet working & $13(43.33 \%)$ \\
& $17(56.7 \%)$
\end{tabular}

Level of eduacation, freq(\%)

Elementary school

$3(10 \%)$

Junior high school

$2(6.7 \%)$

High school

$18(60 \%)$

University

$7(23.3 \%)$

Disease duration (years)

$4.21(0.08-16)^{* *}$

MoCA-Ina Score

$24.97 \pm 3.14^{*}$

*: normal distribution data (mean $\pm \mathrm{SD}){ }^{* *}$ : not normal distribution data (median; min-max)

MoCA-Ina test resulted 15 subjects with cognitive impairment $($ Score $<26)$ and 15 subjects without congnitive impairment $(50 \%)$ (Score $\geq 26)$. Cognitive impairment is found mostly in delayed recall test $(86.7 \%)$, followed by attention (60\%), linguistic (56,67\%), abstraction (53,33\%), and visuospatial/executive ability $(36,67 \%)$.

Most patients $(86.67 \%)$ had no problem in immediate recall test. Meanwhile, for delayed recall test only 4 subjects $(13.33 \%)$ are able to recall completely. We found one patients who unable to recall in immediate recall test but can recall completely without any clues in delayed recall test. (Table 2)

Table 2. Distribution of Recall Ability in SLE patient

\begin{tabular}{ccc}
\hline Type of recall & $\begin{array}{c}\text { Able to recall } \\
\mathrm{N}(\%)\end{array}$ & $\begin{array}{c}\text { Unable to recall } \\
\mathrm{N}(\%)\end{array}$ \\
\hline Immediate recall & $26(86.67 \%)$ & $4(13.33 \%)$ \\
Delayed recall & $4(13.33 \%)$ & $26(86.67 \%)$ \\
\hline
\end{tabular}

From 26 SLE patients who unable to recall in delayed recall test, 24 patients $(92.3 \%)$ was able to recall after given some clues.

Table 3 shows that memory impairment occured in all male patients and more often found in patients who had got married, working, and had longer duration of illness. We found memory impairment in all subjects who have low level education (elementary school) and all subjects who have very high level education (university). Memory impairment were also occured more often in patients with age ranged from 34 to 45 and above 55 years old, as displayed in Table 4.

Table 3. The distribution of delayed memory impairment based on characteristic

\begin{tabular}{lcccc}
\hline \multicolumn{1}{c}{ Characteristic } & $\begin{array}{c}\text { Able to } \\
\text { recall N=4 }\end{array}$ & $\begin{array}{c}\text { Unable to } \\
\text { recall N=26 }\end{array}$ & $\begin{array}{c}\text { Total } \\
\mathrm{N}=30\end{array}$ & $\begin{array}{c}\text { Memory } \\
\text { impairment }\end{array}$ \\
\hline $\begin{array}{l}\text { Gender } \\
\text { Male }\end{array}$ & 0 & 3 & 3 & $100 \%$ \\
$\quad$ Female & 4 & 23 & 26 & $85.18 \%$ \\
$\begin{array}{l}\text { Work } \\
\text { Working }\end{array}$ & 0 & 13 & 13 & $100 \%$ \\
$\quad$ Not Working & 4 & 13 & 17 & $76.47 \%$ \\
$\begin{array}{l}\text { Marital status } \\
\text { Married }\end{array}$ & 2 & 7 & 9 & $90.47 \%$ \\
$\quad$ Not yet married & 2 & 19 & 21 & $77.77 \%$ \\
Level of education & & & & \\
$\quad$ Elementary school & 0 & 3 & 3 & $100 \%$ \\
$\quad \begin{array}{l}\text { Junior high school } \\
\text { High school }\end{array}$ & 1 & 1 & 2 & $50 \%$ \\
$\quad$ & 3 & 15 & 18 & $83.33 \%$
\end{tabular}




\begin{tabular}{lllll}
$\begin{array}{l}\text { University } \\
\text { Duration of illness }\end{array}$ & 0 & 7 & 7 & $100 \%$ \\
$<3$ years & 2 & 11 & 13 & $84.61 \%$ \\
$\geq 3$ years & 2 & 15 & 17 & $88.23 \%$ \\
\hline
\end{tabular}

Table 4. The distribution of delayed recall memory impaiment based on age group

\begin{tabular}{ccccc}
\hline Age & $\begin{array}{c}\text { Able to recall } \\
\mathrm{N}=4\end{array}$ & $\begin{array}{c}\text { Unable to } \\
\text { recall N=26 }\end{array}$ & $\begin{array}{c}\text { Total } \\
\mathrm{N}=30\end{array}$ & $\begin{array}{c}\text { Memory } \\
\text { impairment (\%) }\end{array}$ \\
\hline $15-24$ & 1 & 5 & 6 & 83.33 \\
$25-34$ & 2 & 7 & 9 & 77.77 \\
$35-44$ & 0 & 8 & 8 & 100 \\
$45-54$ & 1 & 5 & 6 & 83.33 \\
$\geq 55$ & 0 & 1 & 1 & 100 \\
\hline
\end{tabular}

\section{Discussion}

Most SLE patients at Hasan Sadikin General Hospital are female with ratio between female and male 9:1. This finding is consistent to study conducted by Ortona that obtained the SLE ration between female and male 8-15:1. The high incidence rate in female is possibly caused by the influence of sex hormon, mainly estrogen. Previous studies have reported that major SLE patients were female in reproductive age. This fact is suitable with the result of our study ${ }^{7}$

Seventeen SLE patients does not work $(56.67 \%)$ or stop working after being diagnosed as SLE. Study conducted by Panopalis,et al. mentioned that SLE patients were not able to work due to 2 factors, neurocognition disorder and depression. ${ }^{8}$ Study conducted by Utset,et al also mentioned that $31 \%$ SLE patient from 6 medical institution in United States of America were unable to work. ${ }^{9}$ Further, study conducted by Apenzeler,et al explained that the reasons made SLE patients unable to work were fatigue, pain, and coginitive impairment. ${ }^{10}$

Fifteen SLE patients (50\%) have mild congnitive impairment with MoCA-Ina total score $<26$, the most impaired domain is delayed recall. Study conducted by Mahdavi,et al in Iran showed a lower prevalence of cognitive impairment in SLE patient, which was about $33.3 \%$, with domain impairment in orientation, linguistic, and delayed recall. ${ }^{11}$ Hawro,et al study with Mini Mental State Examination (MMSE) and Clock Drawing Test (CDT) in 52 SLE patients, found only 5 patients $(9.62 \%)$ had cognitive impairment (MMSE score $<27){ }^{12}$ Characteristics of cognitive impairment in SLE patients denoted by decreased concentration ability, memory, learning, verbal or non-verbal fluency, language, visuospatial ability and motoric and is probably caused by damage on fronto-subcortican circuit. ${ }^{1}$ The various result in this cognitive assessmet could have been caused by the differences in age and level of education of the subjects, as well as the measuring tools and cut off point used.

Memory impairment is one of the most common cognitive symptomps. ${ }^{3}$ Kozora conducted Paced Auditory Serial Addition Test (PASAT) in 73 SLE patients and found that 21 patients (29\%) have PASAT total T-scores below 40 which indicated working memory impairment. ${ }^{13}$ Process of memory formation consisted of encoding, retention or storage, and retrieving information. Encoding and retrieving process occured in prefrontal cortex, meanwhile retention process occured in hippocampus. ${ }^{14}$

For the MoCA-Ina interpretation, if subjects enable to recall after giving clues either a categorical or multiple choice clues, it indicates that encoding and storage process are decent, but retrieving process is impaired. This process is quite important for a person in making decision, working, and interacting with others. ${ }^{15}$ Most of our subjects could recall after the clues which indicating that the disturbance in memory processing is in the retrieval phase. The finding is quite similar to the findings in study conducted by Paran, et al in which memory performance of SLE patients was worse than control when tested using Rey Auditory Verbal Learning Test (RAVLT). The shortage was especially noticeable in delayed recall part and recognition part which indicated retrieval process impairment. The symptoms caused by this memory impairment pattern is reported similar with the symptoms of patients experienced frontal lobes impairment. ${ }^{15}$

De Melo, et al. reported that memory impairment of SLE patients was more frequently occured in older patient and was not influenced by the level of education. ${ }^{16}$ Whereas, several studies showed that demographic factors, disease duration, and disease activity did not influence memory impairment in SLE patient. ${ }^{15-17}$ The report is accordance with the result of our study which memory impairment was found inconsistent with the level of education and patients' age. Works, marriage, and duration of illness seems have slight influences on memory impairment of SLE patients. Memory impairment might be caused by many other factors in addition to demographic characteristics, such as drugs' effects, psychological condition during examination, SLEDAI score, and the level of circulating antibody. Unfortunately, these factors were not assesed in this study.

Memory impairment in SLE patient is affected by the existance of autoantibody that attacked the N-Methyl-DAspartate (NMDA) receptor and arteritis mechanism. ${ }^{15,18}$ Several antibodies that might have contribution in memory impairment are anti-DNA and anti-NMDA receptor subtype 2 (anti-NR2). Anti-DNA and anti-NR2 antibody will bound to NR2A and NR2B subunit of NMDA receptor. When antibodies bound to NMDA receptor, the cells are stimulated to apoptosis, thus the transmission of neutransmitter will not be occured. ${ }^{2}$, ${ }^{3}$ Other study showed that memory impairment in SLE can be caused by vasculopathy, particularly on microvascularization in prefrontal lobes. Vascular endothelial wall is damaged by chronic inflamation caused by the deposition of immune complexes. The inflammation would reduced distribution of oxygenated and nutrition-rich blood to the brain which cause cerebral ischemia and memory impairment. Vasculopathy that occured in fronto-subcortical circuit may result in cognitive and memory impairment. ${ }^{18,19}$ 
The limitation of this study is the limited sample available, therefore conducting analytical study will not be possible. Moreover, the cross-sectional design can not explain the causality association between variables. In addition, other factors that might affect cognitive and memory impairment, such as the drugs effects, psychological condition, SLEDAI score, and the existence or the level of spesific autoantibody were not analyzed due to some limitations.

\section{Conclusion}

About $50 \%$ of SLE patients have cognitive impairment with delayed recall being the most frequently impaired domain followed respectively by attention, linguistic, abstraction, and visuospatial/executive ability. Most subjects (92.3\%) were able to recall completely after given clues which indicated that the disturbance of memory process was occured in retrieval process.

It is necessary to conduct further study with larger samples along with analyzing the factors that contribute to cognitive and memory impairment in SLE patient. Moreover, cognition and memory assesment should be done intergratedly in order to do early prevention for cognitive impairment so that the quality of life of SLE patient could be improved. MoCA-Ina examination is a promising modalities used to assesed cognitive and memory impairment in SLE patients which have similar quality as spesific complex memory neuropsychological test.

\section{References}

1. Conti F, Alessandri C, Perricone C, Scrivo R, Rezai S, Ceccarelli F, et al. Neurocognitive dysfunction in systemic lupus erythematosus: Association with antiphospholipid antibodies, disease activity and chronic damage. PLoS One. 2012;7(3):e33824.

2. West SG. Clinical aspects of the nervous system. In: Wallace D, Hahn $\mathrm{BH}$, editors. Dubois' lupus erythematosus and related syndromes. 8 ed. Philadelphia, PA: Elsevier Health Sciences; 2012. p 368-81.

3. Kowal C, Degiorgio LA, Lee JY, Edgar MA, Huerta PT, Volpe BT, et al. Human lupus autoantibodies against nmda receptors mediate cognitive impairment. Proc Natl Acad Sci U S A. 2006;103(52):19854-9.

4. Prasetyo BT, Lumempouw SF, Ramli Y, Herqutanto. Nilai normal montreal cognitive assesment versi indonesia (MoCA-Ina). 2011;29(1):14.

5. Julayanont P, Phillips N, Chertkow H, Nasreddine ZS. Montreal cognitive assessment (moca): Concept and clinical review. In: Larner JA, editor. Cognitive screening instruments: A practical approach. London: Springer London; 2013. p. 111-51.
6. Adhikari T, Piatti A, Luggen M. Cognitive dysfunction in sle: Development of a screening tool. Lupus. 2011;20(11):1142-6.

7. Ortona E, Pierdominici M, Maselli A, Veroni C, Aloisi F, Shoenfeld Y. Sexbased differences in autoimmune diseases. Annali dell'Istituto Superiore di Sanità. 2016;52(2):205-12.

8. Panopalis P, Julian L, Yazdany J, Gillis JZ, Trupin L, Hersh A, et al. Impact of memory impairment on employment status in persons with systemic lupus erythematosus. Arthritis Care \& Research. 2007;57(8):1453-60.

9. Utset TO, Baskaran A, Segal BM, Trupin L, Ogale S, Herberich E, et al. Work disability, lost productivity and associated risk factors in patients diagnosed with systemic lupus erythematosus. Lupus science \& medicine. 2015;2(1):e000058.

10. Appenzeller S, Cendes F, Costallat LT. Cognitive impairment and employment status in systemic lupus erythematosus: A prospective longitudinal study. Arthritis Rheum. 2009;61 (5):680-7.

11. Mahdavi Adeli A, Haghighi A, Malakouti SK. Prevalence of cognitive disorders in patients with systemic lupus erythromatosus; a crosssectional study in rasoul-e-akram hospital, tehran, iran. Arch Iran Med. 2016;19(4):257-61.

12. Hawro T, Krupińska-Kun M, Rabe-Jabłońska J, Sysa-Jędrzejowska A, Robak E, Bogaczewicz J, et al. Psychiatric disorders in patients with systemic lupus erythematosus: Association of anxiety disorder with shorter disease duration. Rheumatol Int. 2011;31(10):1387-91.

13. Kozora E, Arciniegas DB, Duggan E, West S, Brown MS, Filley CM. White matter abnormalities and working memory impairment in systemic lupus erythematosus. Cogn Behav Neurol. 2013;26(2):63-72.

14. Brewer JB, Gabrieli JD, Preston AR, Vaidya CJ, Rosen AC. Memory. In: Goetz CG, editors. Textbook of clinical neurology. 3 ed. Chicago: Saunders Elsevier; 2007. p 63-78.

15. Paran D, Litinsky I, Shapira-Lichter I, Navon S, Hendler T, Caspi D, et al. Impaired memory and learning abilities in patients with systemic lupus erythematosus as measured by the rey auditory verbal learning test. Ann Rheum Dis. 2009;68(6):812-6.

16. de Melo LF, Da-Silva SL. Neuropsychological assessment of cognitive disorders in patients with fibromyalgia, rheumatoid arthritis, and systemic lupus erythematosus. Rev Bras Reumatol. 2012;52(2):181-8.

17. Maneeton B, Maneeton N, Louthrenoo W. Cognitive deficit in patients with systemic lupus erythematosus. Asian Pac J Allergy Immunol. 2010;28(1):77-83.

18. Shapira-Lichter I, Vakil E, Litinsky I, Oren N, Glikmann-Johnston Y, Caspi $D$, et al. Learning and memory-related brain activity dynamics are altered in systemic lupus erythematosus: A functional magnetic resonance imaging study. Lupus. 2013;22(6):562-73.

19. Shucard JL, Gaines JJ, Ambrus J, Jr., Shucard DW. C-reactive protein and cognitive deficits in systemic lupus erythematosus. Cogn Behav Neurol. 2007;20(1):31-7. 